\title{
TELEMEDICINEEXPERIENCEREPORT:ORIENTATIONAND MONITORING OF PATIENTS SEEN AT THE RHEUMATOLOGY OUTPATIENT CLINIC OF A SUS TERTIARY HEALTH SERVICE
}

Amanda Cacaes Modesto Accioly ${ }^{1,}$, , Diego Fernandes de Abreu, Jeferson Gomes de Andrade ${ }^{1}$, Raíssa Josefa Pereira de Moura', Renata Karine Pedrosa Ferreira', Alessandra de Sousa Braz', Danielle Christinne Soares Egyto de Brito', Eutília Andrade Medeiros Freire ${ }^{1}$

1. Universidade Federal da Paraíba, João Pessoa (PB), Brazil.

*Corresponding author: amandacmaccioly@gmail.com

\section{BACKGROUND}

Autoimmune diseases affect around 3\% of the world population, with high rates of morbidity and mortality. Most of them are chronic diseases that require intensive monitoring in order to reduce damage with better control of the pathology. In March 2020, the World Health Organization declared a state of emergency in health due to the pandemic of the new coronavirus (SARS-CoV-2). Faced with this situation and the consequent need to realize and reaffirm social distance, teleorientation stood out as a form of care of great relevance, from which it is possible to monitor patients, bring them closer to doctors avoiding displacement and provide access to the hospital when it is really necessary.

\section{MATERIALS AND METHODS}

Students and teachers, members of an academic league of rheumatology, provided teleorientation through the Instagram platform for patients seen at the rheumatology outpatient clinic of a Unified Health System (SUS) tertiary health service, during the period from June 4 to September 6, 2020. All services performed followed the recommendations of the Brazilian Ministry of Health (Ordinance No. 467 of March 20, 2020). The students systematized the patients' data through Instagram, storing it in a document shared with the other members of the project. The discussion about the patient's demand occurred through WhatsApp and phone calls, and the guidance was explained through Instagram. Demands that could not be resolved online were directed to doctors on call at the hospital's outpatient clinic or forwarded to other health services.

\section{RESULTS}

One hundred eighty-seven consultations were concluded, 81 related to teleorientation activities and 52 to telemonitoring activities. Of the remaining 54 patients, 42 needed to seek assistance in person at the hospital, 12 were instructed to seek an emergency service and one of them was positive for COVID-19. The main points of teleorientation carried out revolved around the items: vaccination campaign for influenza 2020; return to outpatient activities at the hospital; renewal of revenues and reports and doubts related to COVID-19 and the pathologies presented. Telemonitoring involved the following rheumatological pathologies: systemic lupus erythematosus, rheumatoid arthritis, psoriatic arthritis, ankylosing spondylitis, Sjögren's syndrome, systemic sclerosis, fibromyalgia and lupus nephritis. The procedures were individualized and taken after clinical discussion of the case with the rheumatology team.

\section{CONCLUSION}

The project promoted harm reduction to patients, contributed to social distance due to the pandemic of COVID-19, guiding and monitoring from a distance through clinical and laboratory evaluation and clarifying doubts. 